\title{
The Influence of Organisational Culture on Firms' Effectiveness
}

\author{
Rukevwe J. Olughor \\ Department of Business Administration, Ajayi Crowther University, Oyo. Nigeria
}

\begin{abstract}
Organisational culture has become increasingly prominent in all sectors of industry. It is proposed that if improvements in performance and quality of work are to be achieved, basic and procedural changes must be accompanied by changes in culture. Therefore, there arose a need for a better understanding about the nature of organisational culture and how it can be explored for organisation's advantage. The study adopted a survey design whereby questionnaire was administered to 200 respondents from the banking sector. The study used items drawn from the Denison organisational culture survey to measure culture and effectiveness. The findings from the study showed that the response rate is $90 \%$ and that mission has the strongest contribution to culture.
\end{abstract}

\section{Induction}

Hofstede, $(1984,1991)$ an expert in cross cultural management, defines culture as "the collective programming of the mind, which distinguishes one human group from another ... Culture in this sense, includes systems of values, and values are among the building blocks of culture." Culture then is seen as the disposition of organisations which according to (Wilderom, Berg and Peter, 2004) "holds the organisation together and encourages employees not only to perform well but also to feel committed to the organisation."Culture plays a crucial role in the life of both organisational members and their operations.For the purpose of this study, it will be viewed as a framework that guides organization member'sbehaviourin accomplishmentof their goals.

Goals and objectives are necessary for survival and healthy stability of any organization which is achieved through its human resources thathelps to make a difference in firm's effectiveness.People in organisations are guided by beliefs, ideas and meaning that are inherit in the organization and this leads to members' behaviourally ways of thinking, feeling and acting that affects the organisation's outcome (Yusof and Ali, 2000; Saeed and Hassan, 2000, Smircich, 1985).Thus, realizing firms' effectiveness in the face of constrains and challenges confronting the business environment,managers needto understand the organisation's culture in order to straighten activities in a most creative way. Tannenbaum and Kahn (2000) postulated that a firm's effectiveness is the capacity of the organization to successfully cope with the resources for the accomplishment of the specified goals. Consequently a shared purpose of the organisation couldstart with matching its resources withits goals and objectives and it achievement will depend in part on the fit between individuals and the culture of the organisation. Given that today's organisations are characterized by fast moving environment and internal workforce diversity, the management of culture in increasing organization's effectiveness cannot be underrated as supported by Chow (2001), who stated that organisational culture influences a range of organizationally and individually desires outcomes such as commitment, loyalty, turnover intent and satisfaction leading to firm's effectiveness. Thus, the study is intended to investigate the influence of culture on effectiveness in the banking industry in Nigeria. This study will be a contribution to the literature on culture in the developing countries which haveonly 5 percent of the studiestesting organizational theories done in developing countries (Farashahi et al., 2005).

Achieving effectiveness is fundamental to managers and employees as it help to measure how successful firms realize their missions through their core strategies (McCann, 2004) and this exercise will be beneficial to the business from the understanding of organisational culture as a background factor. This study employed the cultural framework development by Denison and his colleagues (Denison, 1990; Denison \& Mishra, 1995; Fey and Denison, 2003; Denison, et al., 2004) which is very essential to the relationship between organizational culture and effectiveness.

\section{Literature Review}

Organisational culture which is also referred to as organisational climate or corporate culture has been linked to performance (Silverzweig and Allen 1976). Organisational culture has been defined differently by various researchers due to the obscurity in the field of anthropology and sociology (Cameron and Ettington 1988). Although, there are similarities in this field as regard culture but the difference is that while the literature on anthropology views culture as something the organization is, the literature on sociology views culture as something an organization has (Cameron and Ettington 1988). Some definitions of culture include the followings: 
-Distinct and locally shared social knowledge (Wilkins and Ouchi, 1983) -A shared appreciation system and set of beliefs that help distinguish aspects of situations from one another (Sapienza, 1988)

-The pattern of basic assumptions that a group has invented, discovered, or developed in learning to cope with its problems of external adaption and internal integration (Schein, 1984).

-The amalgam of shared values, behavior patterns, mores, symbols, attitudes, and normative ways of conducting business that differentiate one organization from all others (Tunstall,1985).

-A pattern of shared tacit assumptions that was learned by a group as it solved its problems of external adaption and internal integration that has worked well enough to be considered valid and, therefore, to be taught to new members as the correct way to perceive, think and feel in relation to those problems (Schein 2009).

The review of literature has shown that culture makes the difference among organisations and their output (Daniels et al., 2004; Piercy et al., 2004). The management of culture has been found to be used strategically for competitive advantage. Thus organisational culture has been argued as a management philosophy and a way of managing organisations to improve their overall effectiveness and performance (Kotter and Heskett, 1992). It is essential for maximizing the value of human capital and success of organizational change. Schein (1992) suggested that in addition to greater needs to adapt to external and internal changes, organizational culture has become more important, because intellectual as opposed to material assets now constitute the main source of value and that maximizing the value of employees will require a culture that promotes their intellectual participation.

The complication associated in today's competitive business environment undoubted entails continuous improvement of the organisational effectiveness which requires an understanding of the organisation culture. According to researchers, top performance of organisations increasingly demands excellence in all areas, including leadership, productivity, and adaptation to change, process improvement, and capability enhancement (knowledge, skills, abilities, and competencies). However, in the literature, researchers have noted that organisations were likely to experience tension among organisational effectiveness attributes (Rohrbaugh, 1983; Quinn and Rohbaugh, 1983 and Quinn, 1988) along the continuum of level of stability, a need to be flexible and adaptable, degree of freedom and autonomy, rational and non-rational structure. Consequently, employees use their knowledge and skills to adapt to organisational expectations, procedures and expected level of performance. They concluded that effectiveness depended upon the ability of an organization, and its managers, to strike the right balance among these critical attributes, as required by the organisation's objectives and situation.

Denison and his colleagues (Denison, 1990; Denison \& Mishra, 1995; Fey and Denison, 2003; Denison et al., 2004) developed and empirically supported a theory of organizational cultures and effectiveness that identifies four cultural traits that arepositively related to organizational performance viz involvement, consistency, adaptability, and mission. The Involvement refers a function of building employees competence, engagement and responsibility. It is a trait that reflects the level of contribution of the members of the organization in decision making related to organizational goals. Consistency refers to whether the organization is well coordinated, have a strong and organized internal culture that is understood by the members of the organization.Adaptability reflects the extent to which an organization is able to adapt quickly to the changes from the external environment, including customers and the marketplace.Mission refers to the existence of a shared definition of the function and purpose of the organization and members. The Mission trait is useful in identifying whether you are in danger of shortsightedness or you are equipped with systematically defined strategic and action plans.

Relating this model to 764 organization's top executives, Denison and Mishra (1995) showed that the four cultural traits were correlated to numerousmeasuresof effectiveness. They found that profitability was most highly correlated with the traits of mission and consistency. While innovation was most highly associated with the traits of involvement and adaptability, and sales growth was most highly associated with the traits of adaptability and mission. Petty et al. (1995) found that a cultural emphasis on cooperation and teamwork were conducive to organizational effectiveness.In the exploratory model of the relation between organizational culture and performance Marcoulides and Heck (1993), it was found that task organization had a positive direct effect on performance. In addition, Ahmad, (2012) in an exploratory study of employees in COMSATS Institute of Information Technology, Pakistan showed a relationship between organisational culture and performance management practices.

The study is aimed at investigating the influence between organisational culture and effectiveness. Denison's model proposes that organisations with a higher combined measure of thefour cultural traits show higher levels of performance. Therefore, the hypotheses for this study are as follows:

H1:Organizational Culture has a significantly positiverelationship with effectiveness. 
H2: Cultural traits of involvement, consistency, adaptability, and mission in organisations exert a significantly positive influence on effectiveness.

\section{Methodology}

The study adopted a survey research designed to conduct an investigation to determine if organisational culture is related with perceived organisational effectiveness. The study wascarried out by collectingprimary data with the help ofquestionnaire disseminated to 200 employees in Guaranty Trust Bank in Oyo state, Nigeria. 180 usable responses were received.

Measures

For the purpose of this study items were drawn from the Denison OrganizationalCulture Survey (Denison and Mishra 1995, Denison and Neale 1996, Denison et al. 2002) measuring organisational culturewhich uses 60 items on a five point Likert scale with anchors strongly disagree $(=1)$ to strongly agree (=5) was used.This structure focuses on cultural traits of involvement,consistency, adaptability, and mission which were revalidated and the cronbach alphas were: involvement .90 , consistency .93 , adaptability .91 , mission .97 and organisational effectiveness .95. In line with Denison and Mishra (1995), effectiveness was measured using five-point Likert items, ranging from 1 =poor to $5=$ excellent. These items included overall performance, market share, sales growth, profitability, employee satisfaction, quality of products and services, and new product development.

\section{Analysis of the Data}

Table 1 shows the summary of the regression analysis that seeks to establish the relationship between Cultural traits of involvement, consistency, adaptability, and mission and organisational effectiveness. With an adjusted R -squared of 0.195 percent, it means that involvement, consistency, adaptability, and mission and organisational effectiveness. With an adjusted explain about $20 \%$ of the variations in organisational effectiveness. The F value of 10.586 indicates that the overall regression model is significant hence it has some explanatory value. This indicates that there is a significant relationship between the predictor variables of involvement, consistency, adaptability, and mission (taken together) and organisational effectiveness.

Table 1: Analysis of variance (ANOVA) Results

\begin{tabular}{|l|l|l|l|l|l|}
\hline Model & Sum of Squares & DF & Mean Square & F & Sig. \\
\hline Regression & 1081.960 & 4 & 270.490 & 10.586 & .000 \\
Residual & 4471.684 & 175 & 25.552 & & \\
Total & 5553.644 & 179 & & & \\
\hline
\end{tabular}

a. Predictors: (Constant), Mission, Involvement, Consistency, Adaptability

b. Dependent Variable: organisational effectiveness

$\mathrm{R}=.441$

$\mathrm{R}^{2}=.195$

Adj $R^{2}=.176$

Table 2 shows the results of the regression analysis based on the sign of the coefficient and the t-ratio. From the analysis the constant has a t-ratio of 9.446. This indicates that the other factors that affect organisational effectiveness and have not been included in the model are statistically significant in determining its performance. The constant is also positively related to organizational effectiveness implying that the impact of these factors which are not in the model will impact on effectiveness positively.

Table 2: Regression Coefficient

\begin{tabular}{|l|l|l|l|l|l|}
\hline \multirow{2}{*}{ Model } & \multicolumn{2}{|l|}{ Unstandardized Coefficient } & $\begin{array}{l}\text { Standardized } \\
\text { Coefficient }\end{array}$ & \multirow{2}{*}{ T } & \\
\cline { 2 - 5 } & $\mathrm{B}$ & Std. Error & & & \\
\hline (Constant) & 20.854 & 2.208 & & 9.446 & .000 \\
Involvement & $-4.459 \mathrm{E}-02$ & .069 & -.057 & -.647 & .518 \\
Consistency & -.145 & .081 & -.195 & -1.783 & .076 \\
Adaptability & .131 & .075 & .186 & 1.748 & .082 \\
Mission & .276 & .049 & .420 & 5.572 & .000 \\
\hline
\end{tabular}

aDependent Variable: Organisational effectiveness

The result below shows the relative contribution of each of the independent variables on the dependent: Involvement $(\mathrm{t}=-.647, \mathrm{P}>.05)$, Consistency $(\mathrm{t}=-.1783, \mathrm{P}>.05)$, Adaptability $(\mathrm{t}=1.784, \mathrm{P}>.05)$, and Mission $(\mathrm{t}=5.572, \mathrm{P}<.05)$, respectively. Hence, only Mission was found significant while Involvement, Consistency and Adaptability were not. 


\section{Conclusion}

The research is mainly aimed to investigate therelationship between organizational culture and organisational effectiveness. Results show that adaptabilityOverall, there is a strong view in the literature that organisational culture leads to increased organisationalperformance. From the analysis, all four cultural dimensions are less highly correlated with organisational effectiveness. In Nigeria, mission is the strongest contribution toward effectiveness. This is supported in the literature with the U.S. results correlates most highly with five of eight effectiveness dimension.

\section{Reference}

[1]. Ahmad, M.S. (2012), "Impact of Organizational Culture on PerformanceManagement Practices Pakistan”. Business Intelligence Journal.

[2]. Chien Min-Huei, A study of the factors effecting organizational effectiveness

[3]. Denison, D.R. (1990), Corporate Culture and Organizational Effectiveness, Wiley, New York, NY.

[4]. Denison, D.R. and Mishra, A.K. (1995), "Toward a theory of organizational culture and effectiveness", Organization Science, Vol. 6, pp. 204-22.

[5]. Denison, D. R. (2000). Organizational culture: Can it be a key lever for driving organizational change. InS. Cartwright \& C. Cooper (Eds.), The handbook of organizational culture. London: John Wiley \& Sons.

[6]. Denison, D.R., Haal and, S. and Goelzer, P. (2004), "Corporate culture and organizational effectiveness: is Asia different from the rest of the world?", Organizational Dynamics, Vol. 33, pp. 98-109.

[7]. Farashahi, M., Hafso, T. and Molz, R. (2005), "Institutionalized norms of conducting research andsocial realities: a research synthesis of empirical works from 1983 to 2002" International Journal of Management Review, Vol. 7 No. 1, pp. 1-24.

[8]. Fey, F. C., \& Denison, R. D. (2003). Organisational culture and effectiveness: Can American theory be applied in Russia?.Organisation Science. 14(6): 686-706.

[9]. Kotter, P. \&Heskett, L. (1992).Corporate Culture and Performance, Macmillan, New York, NY.

[10]. Magee, K. C. (2002). The impact of organizational culture on the implementation of performance management (Doctoral dissertation).Available from Dissertations and Theses database (UMI No. 3047909).

[11]. Marcoulides, G. \& Heck, R. (1993). Organizational culture and performance: Proposing and testing a model. Organization Science, 4(2), 209-225.

[12]. Piercy, N.F., Low, G.S. \& Cravens, D.W. (2004), "Examining the effectiveness of sales management control practices in developing countries", Journal of World Business, Vol. 39 pp.255-67.

[13]. Quinn, R. E., and J. Rohrbaugh. 1983. A Spatial Model of Effectiveness Criteria: Towards a Competing Values Approach to Organizational Analysis.Management Science 29:363- 377.

[14]. Quinn, R.E. 1988. The Competing Values Model: Redefining Organizational Effectiveness and Change.Beyond Rational Management: Mastering the Paradoxes and Competing Demands of High Performance. San Francisco, CA: Jossey-Bass.

[15]. Rohrbaugh, J. 1983. The Competing Values Approach: Innovation and Effectiveness in the Job Service. In Organizational Theory and Public Policy. R.H. Hall and R.E. Quinn (eds).Beverly Hills: Sage.

[16]. Schein, E. H. (1992). Organizational Culture and Leadership. an Francisco: Jossey-Bass.

[17]. Wilderom, C P M., Berg, D V., \& Peter, T (2004), "Defining, Measuring, and Comparing Organizational Cultures". Internal Association for Applied Psychology. 53 (4), 570-582.

[18]. Wilkins, A., W. G. Ouchi. 1983. Efficient cultures: Exploring the relationship between culture and organizational performance. Admin. Sci. Quart. 28 468-481.

[19]. William H. Mobley, Lena Wang and Kate Fang (2005). Organizational Culture: Measuring and in Your Organization. The Link. 